\title{
Tensile Properties of Bamboo Fiber Reinforced Biodegradable Plastics
}

\author{
Shinji Ochi \\ Department of Mechanical Engineering, Niihama National College of Technology, Niihama city, 792-8580, Japan
}

\begin{abstract}
This paper describes tensile properties of bamboo fiber reinforced biodegradable plastics. The unidirectional biodegradable composites were made from bamboo fiber bundles and a starch-based biodegradable resin. The tensile strengths of the composites increased with increasing fiber content up to $70 \%$. The composites possessed extremely high tensile strengths of $265 \mathrm{MPa}$. The fabrication with emulsion-type biodegradable resin contributed to reduction in voids and fiber contacts in the composites. Moreover, heat resistance of bamboo fibers and bamboo fiber reinforced plastics was investigated. As results, tensile strength of both bamboo fiber and bamboo fiber reinforced plastics decreased at $160^{\circ} \mathrm{C}$.
\end{abstract}

Keywords Bamboo Fiber, Biodegradable Composite, Tensile Properties, Heat Resistance

\section{Introduction}

Recently, because of their extensive use in many diverse fields, plastics, including FRP (fiber reinforced plastics) products have become indispensable to our daily lives. However, the primary raw material used in plastic production is petroleum and there are strong social and economic pressures to conserve petroleum resources. Furthermore, because FRP wastes are non-flammable, they must be disposed of in landfills after use, and this contributes to high environmental loads. In order to reduce the environmental load generated from the disposal of used plastic products, significant attention has been placed on biodegradable plastics. These plastics can be completely resolved into water and carbon dioxide by the action of the microorganism, when disposed of in the soil. Moreover, there are no emissions of toxic gases during incineration. Recently, biodegradable plastics have been used in commercial products such as ball-point pens, toothbrushes, garbage bags, fishing lines, tennis racket strings, wrapping paper and many others. The application of biodegradable plastics has been restricted due to their relatively lower strength compared to conventional plastics such as polyacetal and nylon. Over the past few years a considerable number of studies[1-13] have been performed on biodegradable composites containing biodegradable plastics with reinforcements of biodegradable natural fibers. The natural fibers such as flax[1-3], ramie $[3,4]$, jute[3,5], bamboo[6-8], pineapple[9], kenaf[10,11], henequen[12] and hemp[13] were used for reinforcements

* Corresponding author:

s_ochi@mec.niihama-nct.ac.jp (Shinji Ochi)

Published online at http://journal.sapub.org/cmaterials

Copyright (C) 2012 Scientific \& Academic Publishing. All Rights Reserved in these studies.

In this study, bamboo fibers were selected as a reinforcement of the biodegradable composites due to their high strength and excellent thermal stability. In order to increase the fraction of the fibers, emulsion-type biodegradable resin was used as the matrix. The unidirectional fiber reinforced composites were fabricated by hot pressing. Moreover, heat resistance of bamboo fibers and bamboo fiber reinforced plastics was investigated.

\section{Experimental Procedures}

\subsection{Materials}

In this research, fiber bundles of bamboo which have diameter of $100 \sim 300 \mu \mathrm{m}$ and length of $200 \mathrm{~mm}$ were used. Figure 1 shows macroscopic photographs of bamboo fibers. Steam explosion method was used to take out bamboo fibers. Steam explosion is the method when the water contains in bamboo is heated under high temperature and pressure, then bamboo is rapidly released to the atmosphere, so that the water evaporate into steam, result of parenchyma inside the bamboo shattered.

In order to produce biodegradable composites that have high fiber content, a starch-based emulsion-type biodegradable resin (Miyoshi Oil\& Fat Co., LTD.; CP-300) was used. This resin contains fine particles of approximately 4.6 $\mu \mathrm{m}$ in diameter suspended in aqueous solution with a mass content of approximately $40 \%$. Table 1 shows the properties of used biodegradable plastics

\subsection{Tensile Test of Fibers and Heat Treatment}

Figure 2 shows a paperboard prepared to prevent damage to the fiber during its handling. The cross-sectional area of 
fibers was calculated from their diameters measured using an optical microscope. A fiber was glued to the paperboard, which was then carefully gripped by the testing machine, and cut with a thin heated metal wire along the cutting line indicated in Fig. 2. The JIS R 761 method was followed to determine the tensile strength. The tensile test was performed at a strain rate of 0.04 per min. In the current study, ten specimens of natural fibers were prepared and analyzed. A $95 \%$ confidence interval was calculated by statistics analysis.

To establish the best molding conditions, the natural fibers were heated in air using an electric drying furnace at $140^{\circ} \mathrm{C}$, $160^{\circ} \mathrm{C}, 180^{\circ} \mathrm{C}$ and $200^{\circ} \mathrm{C}$ for $15 \mathrm{~min}, 30 \mathrm{~min}, 60 \mathrm{~min}$ and 120 $\min$.

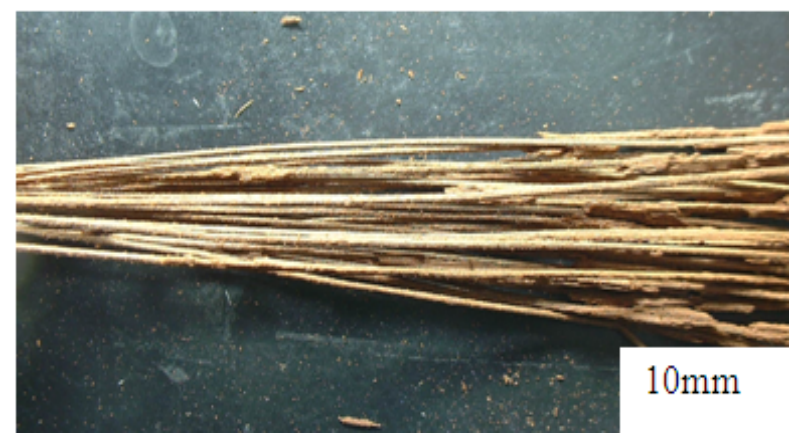

Figure 1. Macroscopic photographs of bamboo fibers

Table 1. Properties of biodegradable plastics

\begin{tabular}{|c|c|}
\hline Density $\left(\mathrm{g} / \mathrm{cm}^{3}\right)$ & 1.18 \\
\hline Softing point $\left({ }^{\circ} \mathrm{C}\right)$ & 57 \\
\hline Waterabsorption(\%) & 2 \\
\hline Tensile strength(MPa) & 10.3 \\
\hline Young's modulus $(\mathrm{MPa})$ & 414.5 \\
\hline
\end{tabular}

\subsection{Molding Method of Biodegradable Composites}

First, preliminary composites were produced by putting the biodegradable resin on the surface of bamboo fibers and drying at $105^{\circ} \mathrm{C}$ for $120 \mathrm{~min}$ in an oven. Next, biodegradable composite specimens were fabricated by hot pressing using a pressing machine. In this process, the preliminary composites were set in a metallic mold and heated to $130^{\circ} \mathrm{C}$ with a flexible heater rolled around the metallic mold. The metallic mold was held at $130^{\circ} \mathrm{C}$ for $5 \mathrm{~min}$ and specimens were hotpressed at $10 \mathrm{MPa}$ for $10 \mathrm{~min}$. The dimensions of the biodegradable composite specimens were $10 \mathrm{~mm} \times 200 \mathrm{~mm} \times 1$ $\mathrm{mm}$ for tensile testing. The volume fraction of bamboo fiber in the specimens was varied from $30 \%$ to $70 \%$.

\subsection{Tensile Test of Bamboo Fiber Reinforced Plastics}

Tensile tests were carried out by using an Instron testing machine (Model 4482). Tensile tests were performed according to JIS K7162 at a strain rate of 0.0143 per min and a gauge length of $70 \mathrm{~mm}$. Figure 3 shows the shape and the dimensions of a tensile specimen. To investigate the heat resistance of bamboo fiber reinforced plastics, bamboo fiber composites were heated at $140^{\circ} \mathrm{C}$ to $200^{\circ} \mathrm{C}$ for 15 to $120 \mathrm{~min}$ in air.

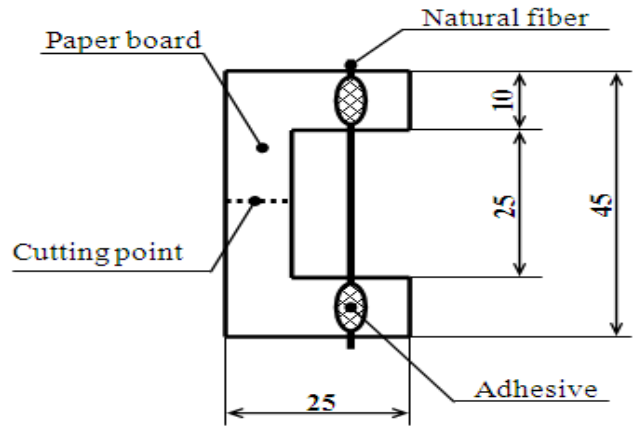

Figure 2. Tensile specimens for bamboo fiber

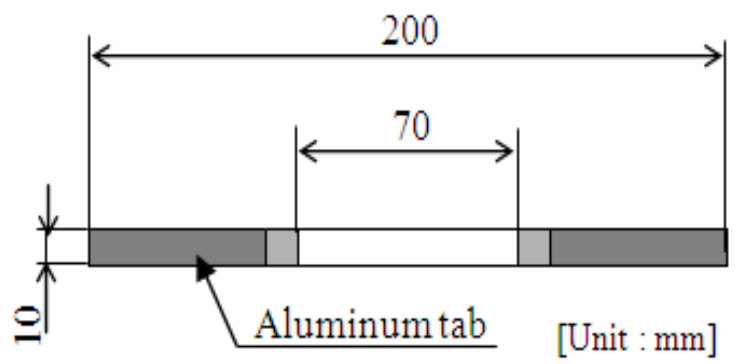

Figure 3. Tensile specimens for bamboo fiber reinforced plastics

\section{Results and Discussions}

\subsection{Mechanical Properties of Heat-Treated Bamboo Fiber}

In order to establish the most suitable molding conditions, mechanical properties of heat-treated bamboo fibers were examined. Figure 4 shows the effect of heat treatment on the tensile strength of bamboo fibers. The average tensile strength of bamboo fibers without heat treatment is $516 \mathrm{MPa}$. At $140^{\circ} \mathrm{C}$, the tensile strength of heat-treated bamboo fibers does not decrease even with longer heating times. the tensile strength of bamboo fiber rapidly decreases at heating temperatures of $180^{\circ} \mathrm{C}$ and $200^{\circ} \mathrm{C}$, however it shows a tendency to decrease gradually at $160^{\circ} \mathrm{C}$. Based on these results, the processing temperature for fabricating bamboo fiber reinforced composites should be kept below $140^{\circ} \mathrm{C}$ in order to prevent strength reduction due to thermal degradation.

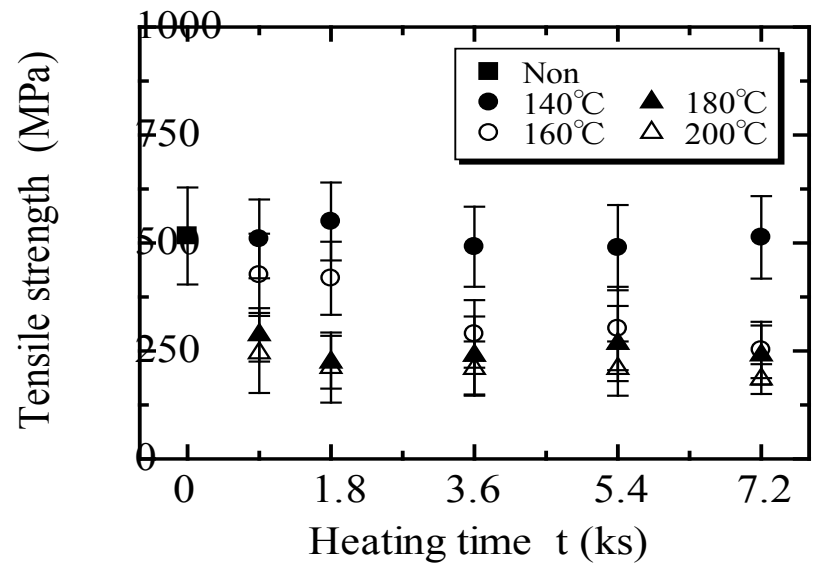

Figure 4. Relationship between tensile strength of Manila hemp fibers and heating time 


\subsection{Microstructure of Biodegradable Composites}

The transverse section and top view of the biodegradable composites with $70 \%$ of fibers are shown in Fig. 5 and Fig. 6 , respectively. From these figures, it can be observed that the distribution of fibers is parallel, and that there are no voids or fiber contacts that would cause a decrease in strength. In previous studies, the composites were fabricated by sandwiching layers of fibers between several resin films. However, with this method it was not possible to fabricate high fiber volume fraction composites as the increase of fiber content led to increased fiber contact. The novel technique presented herein, which uses an emulsion-type biodegradable resin, provides a suitable internal environment for achieving high fiber volume, in which voids and fiber contacts are reduced in the composites.

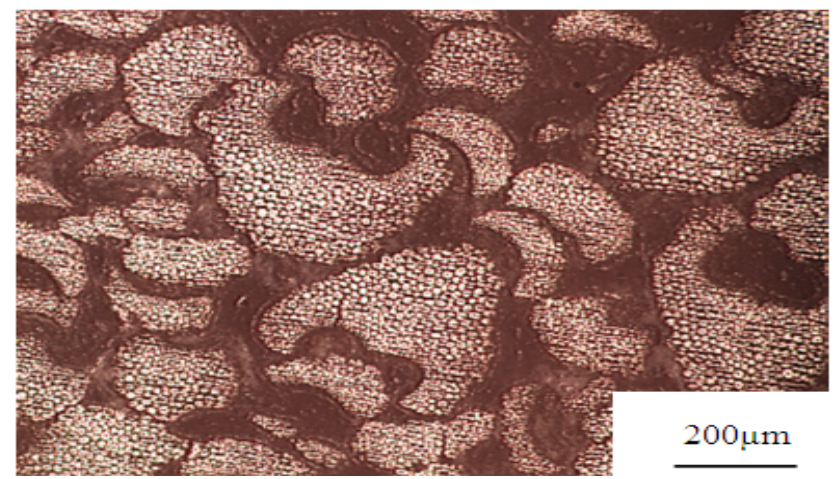

Figure 5. Optical micrograph of transverse section of biodegradable composites with $70 \%$ of fibers

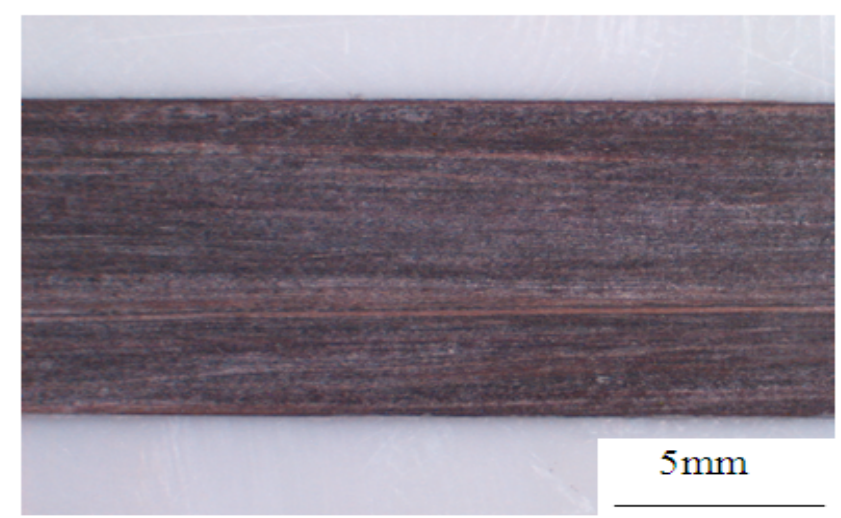

Figure 6. Photograph of top view of biodegradable composites

\subsection{Tensile Strengths of Biodegradable Composites}

Figure 7 shows the relationships between fiber content and tensile strength. From this figure, it can be seen that tensile strengths increase linearly with increasing fiber content. The tensile strengths were $265.5 \mathrm{MPa}$, in the samples with a fiber fraction of $70 \%$. When fiber content is more than $70 \%$, some voids and fiber contacts caused by insufficient amount of resin are observed in the specimen. Therefore, the fiber content used for fabricating bamboo fiber reinforced composites should be kept below $70 \%$.

Table 2 shows the theoretical tensile strength values calculated from the rule of mixtures[14], and experimental values. From this table, experimental strength values are approximately $75 \%$ of the theoretical strength. As shown in Fig. 4, there is a large variation in bamboo fiber strength and lower experimental strength values could be attributed to fracture of low strength fibers.

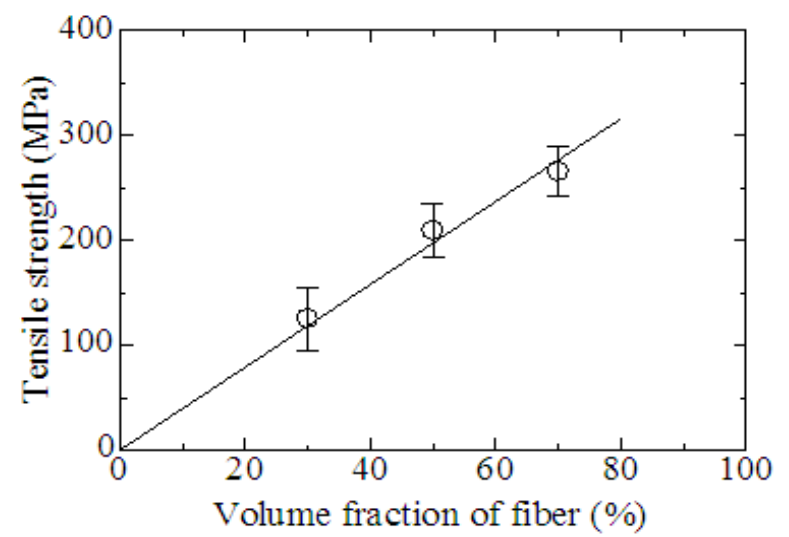

Figure 7. Relationship between tensile strength of unidirectional biodegradable composites and Manila hemp fiber content

Table 2. Comparison of theoretical and experimental value of tensile strength

\begin{tabular}{|c|c|c|c|}
\hline $\begin{array}{c}\text { Volume fraction } \\
\text { of fibers (\%) }\end{array}$ & $\begin{array}{c}\text { Theoretical } \\
\text { strength (MPa) }\end{array}$ & $\begin{array}{c}\text { Experimental } \\
\text { strength (MPa) }\end{array}$ & $\begin{array}{c}\text { Experiment/ } \\
\text { theory (\%) }\end{array}$ \\
\hline 30 & 162.3 & 120.2 & 77.1 \\
\hline 50 & 263.9 & 209.3 & 79.3 \\
\hline 70 & 364.7 & 265.5 & 72.3 \\
\hline
\end{tabular}

Figure 9 shows the relationship between elastic modulus in tensile modes, and fiber content. From this figure, tensile modulus increase linearly with increasing fiber content same as tensile strength. The tensile strengths were 12.4 $\mathrm{GPa}$, in the samples with a fiber fraction of $70 \%$.

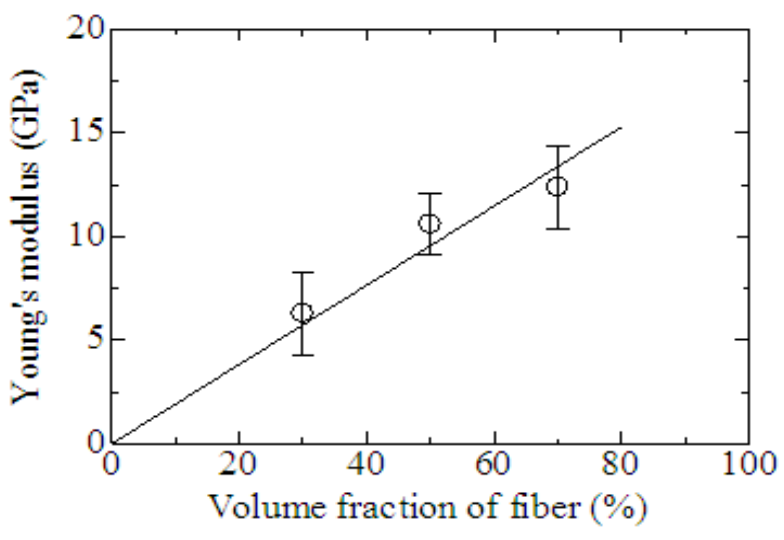

Figure 9. Relationship between elastic modulus and fiber content

\subsection{Mechanical Properties of Heat-Treated Composites}

Figure 10 shows the effect of heat treatment on the tensile strength of bamboo fiber reinforced plastics. From Fig.10, the tensile strength of the composites rapidly decreases at heating temperature of $200^{\circ} \mathrm{C}$, however it shows a tendency to decrease gradually at $180^{\circ} \mathrm{C}$. On the other hand, there is no significant effect of heating time on the tensile strength of bamboo fiber reinforced plastics heat-treated at $140^{\circ} \mathrm{C}$. According to these results, the processing temperature for fabricating natural fiber reinforced plastics should be set below 
$140^{\circ} \mathrm{C}$ for bamboo fibers. These results are the same as the mechanical properties which the natural fiber heat-treated in air, and we found that the tensile strength of composites used as strengthening material the bamboo fiber decrease at $160^{\circ} \mathrm{C}$.

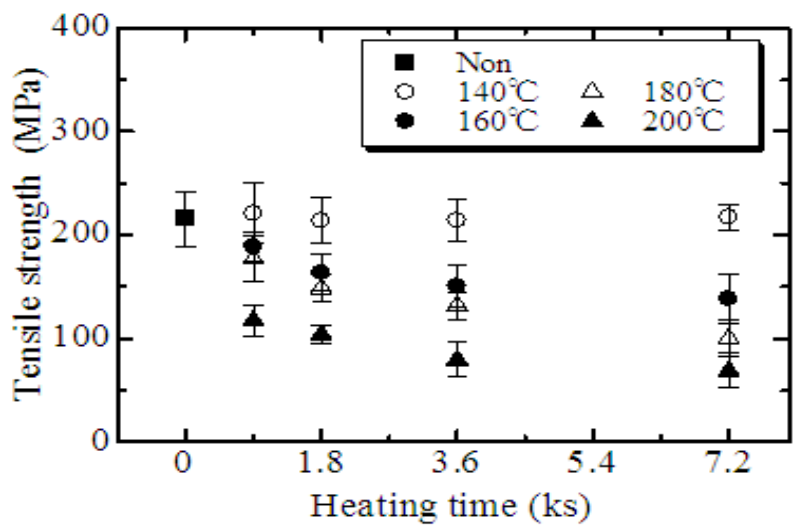

Figure 10. Relationship between tensile strength of bamboo fiber reinforced plastics and heating time

\section{Conclusions}

High strength biodegradable composites were made using an emulsion-type biodegradable resin as the matrix and bamboo fiber bundles as the reinforcement. The results obtained are as follows:

1. The tensile strength of bamboo fibers heat-treated at $140^{\circ} \mathrm{C}$ for $120 \mathrm{~min}$ did not decrease. Thus, $140^{\circ} \mathrm{C}$ are the highest fabrication temperatures that do not affect the strength. The tensile strength of bamboo fiber reinforcd plastics do not decrease below $140^{\circ} \mathrm{C}$, however it rapidly decreases around $180^{\circ} \mathrm{C}$.

2. Unidirectional biodegradable composites fabricated using an emulsion-type biodegradable resin and bamboo fiber bundles with a fiber content of $70 \%$ have high tensile strengths of $265 \mathrm{MPa}$ and tensile modulus of $12.4 \mathrm{GPa}$.

3. The tensile strength and modulus increased linearly with increasing fiber content up to $70 \%$. Thus excellent mechanical properties are achieved for composites fabricated by the novel technique proposed in this study in which the composites are fabricated with an emulsion-type biodegradable resin.

\section{REFERENCES}

[1] Xiaosong Huang, Anil Netravali, Characterization of flax fiber reinforced soy protein resin based green composites modified with nano-clay particles, Composites Science and Technology, Volume 67, Issue 10, p. 2005-2014, 2007
[2] Edwin Bodros, Isabelle Pillin, Nicolas Montrelay, Christophe Baley, Could biopolymers reinforced by randomly scattered flax fibre be used in structural applications, Composites Science and Technology, Volume 67, Issues 3-4, p. 462-470, 2007

[3] M. Wollerdorfer and H. Bader, Influence of Natural Fibers on The Mechanical Properties of Biodegradable Polymers, Industrial Crops and Products, Vol.8, 1998, p. 105-112

[4] Preeti Lodha, Anil N. Netravali, Characterization of stearic acid modified soy protein isolate resin and ramie fiber reinforced 'green' composites, Composites Science and Technology, Volume 65, Issues 7-8, p.1211-1225, 2005

[5] D. Plackett, T. L. Andersen, W. B. Pedersen and L. Nielsen, Biodegradable composites based on polylactide and jute fibres, Composites Science and Technology, Vol. 63, 2003, p. 1287-1296

[6] Okubo, K. and Fujii, T., "Eco-Composites Using Bamboo and Other Natural Fibers and Their Mechanical Properties", Proceedings of International Workshop on "Green" Composites, 2002, p. 17-21

[7] Xiaosong Huang, Anil Netravali, Biodegradable green composites made using bamboo micro/nano-fibrils and chemically modified soy protein resin, Composites Science and Technology, Volume 69, Issues 7-8, p.1009-1015, 2009

[8] Hongyan Chen, Menghe Miao, Xin Ding, Influence of Moisture Absorption on the Interfacial Strength of Bamboo/Vinyl Ester Composites, Composites Part A: Applied Science and Manufacturing, p. 2013-2019, 2009

[9] S. Luo and A. N. Netravali, Interfacial and Mechanical Properties of Environment-Friendly "Green" Composites Made From Pineapple Fibers and Poly (hydroxybutyrate-covalerate) Resin, Journal of Materials Science, Vol.34, 1999, p.3709-3719

[10] Byoung-Ho Lee, Hee-Soo Kim, Sena Lee, Hyun-Joong Kim, John R. Dorgan, Bio-composites of kenaf fibers in polylactide: Role of improved interfacial adhesion in the carding process, Composites Science and Technology, p. 2573-2579 2009

[11] Wanjun Liu, Lawrence T. Drzal, Amar K. Mohanty, Manjusri Misra, Influence of processing methods and fiber length on physical properties of kenaf fiber reinforced soy based biocomposites, Composites Part B: Engineering, Volume 38, Issue 3, p.352-359, 2007

[12] P. J. Herrera-Franco and A. Valadez-González, Mechanical properties of continuous natural fibre-reinforced polymer composites, Composites Part A: Applied Science and Manufacturing, Vol.35, 2004, p. 339-345

[13] A. K. Mohanty, A. Wibowo, M. Misra and L. T. Drzal, Effect of process engineering on the performance of natural fiber reinforced cellulose acetate biocomposites, Composites Part A: Applied Science and Manufacturing, Vol.35, p. 363-370, 2004

[14] Hull and Clyne, An Introduction to Composite Materials Second edition, Cambridge, 1996 